\title{
CON EL HAMBRE A LAS PUERTAS. El ABASTECIMIENTO DE VALENCIA DURANTE LA Guerra de los Dos Pedros (1356-1366)
}

\author{
Pablo Sanahuja Ferrer ${ }^{1}$ \\ Universitat de València
}

\begin{abstract}
Resumen
Este artículo pretende contribuir a la corriente de renovación intelectual que en los últimos años se ha abierto con la llamada nueva historia política. Específicamente, pretende abordar la problemática del hambre en una ciudad durante un conflicto bélico (la Guerra de los Dos Pedros) y, sobre todo, las políticas que sus dirigentes aplicaron y si estas fueron efectivas o no².
\end{abstract}

\section{Palabras clave}

Valencia; Guerra de los Dos Pedros; abastecimiento; asedio; hambre.

\begin{abstract}
This article aims to contribute to the intellectual renewal trend that has opened in recent years with the so-called new political history. Specifically, it aims to address the problem of hunger in a city during a war (the war of the Two Peters) focusing on the policies that their leaders applied and whether they were effective or not.
\end{abstract}

\section{Keywords}

Valencia; War of the Two Peters; supply; siege; starvation.

\section{Resumo}

Este artigo tem como objetivo contribuir para a atual renovação intelectual que, nos últimos anos, teve início com a chamada nova história política. Especificamente, pretende abordar o problema da fome numa cidade durante a guerra (a Guerra dos Dois Pedros) e, acima de tudo, as políticas de seus líderes aplicaram e se eram ou não eficazes.

\section{Palavras-chave}

Valencia; Guerra dos Dois Pedros; o fornecimento; cerco; inanição.

Correo electrónico: pablogeldo7@gmail.com.

2 Los datos inéditos ofrecidos por este estudio proceden de la investigación desarrollada en los fondos del Archivo Municipal de Valencia (AMV), específicamente las actas de las decisiones adoptadas por el gobierno municipal, los Manuals de Consell (M.C.), y los registros de los albaranes del municipio, los Manuals d'Albarans de la Claveria Comuna (C.C.). 


\section{Introducción}

21 de mayo de 1363, Pedro I de Castilla, conocido por muchos como el "Cruel" y por unos pocos como el "Justiciero", vislumbraba las murallas de la capital del Turia desde el mismísimo Palacio Real de Valencia. En esos momentos tan sólo el río y esas murallas se interponían entre él y una ciudad cuya conquista inclinaría la balanza de la guerra definitivamente a su favor. Pero el río era un pobre obstáculo, sus tropas ya lo habían traspasado y rodeaban la urbe allí por donde sus defensas eran más endebles, los arrabales ${ }^{3}$. El rey debía ser consciente de que había llegado más lejos de lo que pensaba llegar en aquella campaña, iniciada en enero en el frente aragonés con la toma de Borja, y ciertamente exitosa al haber partido en dos los territorios de la Corona de Aragón tras tomar Morvedre, pero ahora se encontraba ante una gran urbe y sin armas de asedio con que expugnar sus débiles murallas ${ }^{4}$. No obstante, sí que tenía un arma, quizás la más poderosa de todas, el hambre.

Con este párrafo protagonizado por el monarca castellano queremos introducir nuestro verdadero propósito, determinar el peso del poder público, concretamente el municipio valenciano, en combatir el hambre, es decir, en garantizar el abastecimiento de una ciudad durante un conflicto bélico. Esto implica plantear la guerra como un fenómeno más allá de sus implicaciones políticas.

En las últimas décadas el panorama historiográfico ha sufrido una enorme renovación y progreso, si lo comparamos con las décadas previas, en los dos campos historiográficos entre los que se encuentra el presente trabajo. En primer lugar, la historia de la alimentación, tema que empezó a interesar a los historiadores tras la Segunda Guerra Mundial y el impacto del hambre durante la posguerra. Ya en las décadas de 1960 y 1970 encontramos una serie de artículos impulsados en parte por la renovación historiográfica promovida por la escuela de "Annales"5. En ámbito hispánico Miguel Ángel

\footnotetext{
La segunda muralla de Valencia había sido concluida de manera apresurada y aunque ya rodeaba todos los arrabales, su carácter endeble era patente, nada que ver con la muralla que posteriormente haría gala de monumentos tales como las torres de Quart y de Serranos. Véase al respecto Amadeo SerRa DesfiLis, (2008): "La construcción de las murallas de Valencia en el siglo XIV: ampliación, defensa y administración", Historia de la ciudad V. Tradición y progreso, ed. Colegio Territorial de Arquitectos de Valencia, Valencia, 2008, pp. 79-94; Carolina SÁncheZ-CuTILlas, "La Fàbrica vella, dita de murs i valls", VIII Congreso de Historia de la Corona de Aragón, t. II, vol. 2, Valencia, 1970, pp. 199-219; Vicente MeLió Uribe, La "Junta de Murs i Valls": historia de las obras públicas en la Valencia del Antiguo Régimen, siglos XIV-XVIII, ed. Consell Valencià de Cultura, Valencia, 1991.

4 Pero López de Ayala, Crónicas (ed. de J. L. Martín), ed. Planeta, Barcelona, 1991, pp. 288-290.

5 Valga como ejemplo: Fernand Braudel, "Alimentation et catégories de l'histoire", Annales. Economies. Societés. Civilisations, XVI (1961), Paris, pp. 723-728; Jacob Hermandinguer, Pour une histoire de l'alimentation, col. Cahiers des Annales, 28 (1970), Paris. Ciertos historiadores han sido partícipes de la opinión de que la historia de la alimentación es una mera manifestación de la historia económica y social, opinión que nosotros no compartimos porque la historia de la alimentación no es patrimonio único de la historiografía, también lo es de la literatura gastronómica (considerada su fundadora en la Francia del siglo XVIII), la etnología y la sociología; Jean Louis FLANDRín, "Historia de la alimentación: por una ampliación de las perspectivas", Manuscrits: Revista d'història moderna, 6 (1987), Barcelona, pp. 7-30.
} 
Ladero Quesada recogía en un breve artículo las aportaciones registradas hasta 1980 y verdaderamente marcaba un punto de inflexión en el despertar de esta disciplina con el surgimiento de estudios de mayor calado, como el Ir Col-loqui d'Història de l'Alimentació a la Corona d'Aragó. Edat Mitjana, publicado en 1995 por el Institut d'Estudis Ilerdencs, o el estudio de Juan Vicente García Marsilla: La taula del senyor duc: alimentació, gastronomía i etiqueta a la cort dels ducs reials de Gandia, ed. CEIC Alfons el Vell, Gandía, $2010^{6}$.

Sin embargo, esta historiografía parte del supuesto de que la alimentación no es un mero proceso de nutrición, sino un auténtico fenómeno cultural y socio-económico, lo que aleja esta materia de nuestros más sencillos planteamientos logísticos. Quizás la excepción la encontremos en dos obras que nos marcan el camino y nos sirven de referente, por un lado, Albert CuRTo i Homedes, La intervenció municipal en l'abastament de blat d'una ciutat catalana, Tortosa, segle XIV, ed. Rafael Dalmau, Barcelona, 1988; y, por el otro, Pol Serrahima i Balius, "Wheat provisioning in Barcelona during the Catalan Civil War (1462-1472)", Guerra y carestía en la Europa medieval, Pere Benito i Monclús y Antoni Riera i Melis (coords.), ed. Milenio, Lleida, 2004, pp. 179-204.

Es esta última obra la que nos encauza hacia el segundo campo historiográfico, la "nueva historia política" o "nueva historia militar", es decir, aquella que concibe la guerra como un fenómeno de hondas implicaciones que trascienden las batallas, protagonistas del discurso en la historia política y militar de corte tradicional, para afectar a un cúmulo de situaciones o temáticas. Entre ellas podríamos enumerar la financiera y fiscal, la cultural, la de género, etc. Como podemos ver, ha llegado a ser un campo demasiado amplio, por lo que nos centraremos en aquel que versa sobre la logística de la alimentación.

Como antes adelantábamos, se trata de un campo historiográfico a caballo entre los más potentes de la alimentación y de la guerra, encontrando algún trabajo pionero como el de Manolo Sánchez sobre la fallida campaña de Alfonso el Benigno contra Granada ${ }^{7}$, pero sólo ha sido en la última década cuando este campo (el de la logística) ha comenzado a individualizarse con la publicación de una serie de obras que partían de la problemática

\footnotetext{
6 El artículo de Ladero Quesada al que hacemos referencia es el siguiente, Miguel Ángel LADERo QuesadA, "La alimentación en la España Medieval. Estado de las investigaciones", Hispania, XLV (1980), pp. 211220. Tampoco podemos olvidar a uno de los pioneros dentro de las instituciones caritativas, Prim Bertran, "El menjador de l'Almoina de la Catedral de Lleida. Notes sobre l'alimentació dels pobres lleidetans al 1338”, Ilerda, XL (1979), pp. 89-124. García Marsilla ya había tratado el tema con un estudio publicado en 1993 y que más adelante referenciamos, así como los trabajos de Rubio Vela, uno de los primeros en tratar esta problemática en nuestro país. Puede que las principales novedades se hayan concentrado en los últimos 20 años en el ámbito historiográfico español, pero no así en otros países como Francia, donde tras la rehabilitación de la historia de la alimentación por la escuela de "Annales", produciendo una corriente innovadora que daría sus frutos en la década de 1970 con obras de análisis territorial, citando como ejemplos y en relación a nuestra cronología: Louis StoufF, Ravitaillament et alimentation en Provence aut XIVe et XV siècles, ed. Mouton, París, 1970; François RIPONNIER, "Recherches sur la consommation alimentaire en Bourgogne au XIVe siècle", Annales de Bourgogne, 182 (1974), pp. 65-111.

7 Manuel SÁnchez Martínez, "Guerra y avituallamiento del ejército y carestías en la Corona de Aragón: la provisión de cereal para la expedición granadina de Alfonso el Benigno", Historia. Instituciones. Documentos, 20 (1993), pp. 523-549.
} 
logística de alimentar un ejército en campaña para después examinar las consecuencias en la población y en el mercado. Entre ellas destacan dos: en primer lugar, el ya citado estudio dirigido por Pere Benito i Monclús y Antoni Riera i Melis, Guerra y carestía en la Europa medieval, publicado en el año 2014 y que recoge una serie de artículos de diferentes autores sobre la problemática aquí abordada ${ }^{8}$; en segundo lugar, con un carácter mucho más concreto encontramos el trabajo de Mario Lafuente sobre la expedición aragonesa a Cerdeña para sofocar la revuelta del Juez de Arbórea (1354-1355), especialmente el segundo capítulo, dedicado a la financiación y al aprovisionamiento de la armada, aunque limitado a la aportación aragonesa9 .

Mas no son los únicos, destacando en ámbito italiano Aldo SETtia, Rapine, assedi, battaglie. La guerra nel medioevo, ed. Laterza, Roma-Bari, 2002. Este autor destaca por profundizar en las consecuencias de un ejército en campaña, mientras que la perspectiva urbana ya ha sido abordada parcialmente por Antoni RIERA I Melis, "Crisis alimentarias y preparativos bélicos en las ciudades catalanas durante el último cuarto del siglo XIII", Uomini, paesaggi, storie. Studi di Storia Medeivale per Giovanni Cherubini, Duccio Balestracci, Andrea Barlucchi, Franco Franceschi, Paolo Nanni, Gabriella Piccinni, Andrea Zorzi (coords.), ed. SeB, Siena, II, 2012, pp. 237-246.

\section{La Guerra de los Dos Pedros}

Volvamos ahora con nuestros protagonistas, en el momento en que Pedro de Castilla se disponía a lanzar el hambre contra los valencianos, pero no adelantemos acontecimientos, para comprender cómo se llegó a este punto es necesario que dediquemos unas líneas a explicar el porqué de esa guerra. Todo comenzó por un conflicto marítimo acaecido en Sanlúcar de Barrameda durante el mes de julio de 1356. El atrevimiento del capitán catalán Francesc de Perellós al apresar dos naves piacentinas ante la mismísima presencia del monarca castellano, quien no pudo tolerar esa acción de corso contra los comerciantes que se encontraban bajo su protección, desencadenó una crisis diplomática. Fue este hecho, hasta cierto punto irrelevante teniendo en cuenta la informal guerra de corso que existía entre Castilla y Aragón, el que reabrió viejas heridas a las que se sumaban nuevos agravios. El incidente de Sanlúcar de Barrameda no bastaba para justificar una guerra, para considerarla "justa", eran otras las causas, más profundas y relevantes las que empujaron a Castilla y Aragón al camino de la guerra. No obstante, este hecho fue el casus belli, la chispa que inició la crisis, por lo que no debe ser menospreciado ${ }^{10}$.

\footnotetext{
8 Esta obra no surge de la nada sino que se podría considerar una culminación del esfuerzo dedicado por estos dos directores, destacando la sesión de comunicaciones dirigida por Pere Benito: Acció militar $i$ proveïment durant la guerra civil catalana (1462-1472), sesión celebrada en el marco del coloquio internacional "Crisis en la Edad Media (II): Guerra y carestía", que tuvo lugar en la Universitat de Lleida los días 30 de junio y 1 de julio de 2011.

9 Mario Lafuente Gómez, Guerra en Ultramar. La intervención aragonesa en el dominio de Cerdeña (1354-1355), ed. Institución Fernando el Católico, Zaragoza, 2011.

10 Me limitaré a enumerar de manera resumida las principales causas que explican el enfrentamiento puesto que el propósito de este trabajo no es centrarnos en la historia política: $1^{\circ} \mathrm{La}$ reclamación por parte de Castilla
} 
El conflicto, conocido en la documentación catalana de la época como "guerra de Castella", pero que la posterioridad bautizó como "Guerra de los Dos Pedros" al enfrentar a Pedro I de Castilla y Pedro IV de Aragón (el "Ceremonioso"), se caracterizó por la ausencia de grandes batallas campales. En su lugar, escaramuzas fronterizas, incursiones de devastación del campo enemigo y asedios, muchos asedios, marcaron el ritmo de una guerra en la que Aragón llevó las de perder. Sobre todo cuando el frente aragonés se desplomó en enero de 1363 y Pedro el Cruel inició su exitosa campaña que le llevó a las puertas de Valencia, ciudad a la que llegaría a asediar en dos ocasiones. Si fracasó una primera vez, ¿triunfaría en un segundo intento? En ambas tentativas, el hambre fue su gran aliado ${ }^{11}$.

Es posible que don Pedro conociera la doctrina de Vegecio en virtud de la que provocar la escasez entre los enemigos era la manera más eficaz y menos peligrosa para derrotarlos, a diferencia de una batalla campal, donde lo impredecible podía derivar en una derrota inesperada. El hambre como arma de combate se podía canalizar de dos maneras, bien a través de acciones de desgaste contra el campo enemigo, bien mediante un cerco que impidiera abastecer una plaza asediada ${ }^{12}$.

Por el otro lado, la disponibilidad alimentaria era un condicionante fundamental de las campañas militares, de ella dependía el transcurso de la expedición, el planteamiento de sus objetivos y, por supuesto, su éxito ${ }^{13}$. A la hora de preparar una campaña era necesario acaparar cuanto cereal se pudiera retirándolo del mercado antes de que su

de los territorios del norte del reino de Murcia, incorporados por Jaime II al reino de Valencia; $2^{\circ}$ La cesión de Alacant, Elx, Crevillent y Oriola a Pedro de Castilla por parte de los infantes Fernando y Juan, hecho que violaba la soberanía del reino de Valencia y que estaba íntimamente relacionado con la difícil relación que estos infantes, primos del monarca castellano, mantenían con su hermanastro, el monarca aragonés; $3^{\circ} \mathrm{La}$ escisión de las ramas aragonesas de las órdenes de Santiago y Calatrava, con el nombramiento de maestres propios; $4^{\circ} \mathrm{El}$ ya referido conflicto mediterráneo, con el cruce de alianzas Castilla-Génova y Aragón-Venecia, con la consecuente guerra de corso. Para conocer más extensamente las causas de la guerra véase: Àngel Masià I de Ros, Relación castellano-aragonesa desde Jaime II a Pedro el Ceremonioso, ed. CSIC, Barcelona, 1994; María Teresa Ferrer i Mallol, Entre la paz y la guerra: la Corona catalanoaragonesa y Castilla en la Baja Edad Media, ed. CSIC, Barcelona, 2005; María Rosa MuÑoz Pomer, "Preliminares de la Guerra de los Dos Pedros en el reino de Valencia (1356)", Anales de la Universidad de Alicante. Historia Medieval, 1 (1982), pp. 117-134.

11 Para obtener un mayor conocimiento sobre este conflicto y sus protagonistas recomendamos la lectura de los siguientes trabajos: José Vicente Cabezuelo Pliego, La Guerra de los Dos Pedros en las tierras alicantinas, ed. Instituto de Cultura Juan Gil-Albert, Alicante, 1991, donde se insiste en la cuestión murciana como principal causa del conflicto; Luis Vicente Díaz MarTín, Pedro I el Cruel (1350-1369), ed. Ediciones Trea, Gijón, 1995; Julio VAldeón BARUQue, Pedro I el Cruel y Enrique de Trastámara, ¿̇la primera guerra civil española?, ed. Aguilar, Madrid, 2002. Centrado en el reino de Aragón destacan los trabajos de Mario Lafuente: Mario Lafuente Gómez, Dos Coronas en Guerra: Aragón y Castilla (1356-1366), ed. Grupo CEMA-Universidad de Zaragoza, Zaragoza, 2012; ídem, Un reino en armas: la guerra de los Dos Pedros en Aragón (1356-1366), ed. Institución Fernando el Católico, Zaragoza, 2014. Especialmente interesante resulta este último desde el punto de vista técnico y logístico en cuanto a la defensa militar de un reino medieval.

12 Francisco García Fitz, "Más fuerte que la espada. El hambre como arma y motor de la guerra en la Castilla plenomedieval", Guerra y carestía en la Europa medieval, Pere Benito i Monclús y Antoni Riera i Melis (coords.), ed. Milenio, Lleida, 2014, pp. 35-64.

13 Aldo Settia, Rapine, assedi..., pp. 15-34. 
cotización se disparara, cosa para la que tan sólo hacía falta un mero rumor. Por ello, la iniciativa pública debía adelantarse a los acaparadores privados, o incluso legislar en su contra, para dirigir en su favor los flujos del mercado ${ }^{14}$.

\section{La población de Valencia}

No obstante, el caso de una ciudad reviste una mayor complejidad o relevancia por cuanto sus autoridades no sólo debían alimentar a los soldados que la protegían, sino también garantizar el acceso de la población a la alimentación y a unos precios aceptables. Ésta siempre fue una de las principales preocupaciones de los regidores del municipio, una preocupación no sólo adscrita a los momentos de crisis, como lo fue la guerra con Castilla. Es necesario que nos situemos en el contexto; 1356, la ciudad ha superado la Peste Negra de 1348, cuyo impacto ha sido importante entre la población urbana europea, pero no ha conseguido frenar el proceso en que se encontraba la capital valenciana. Un proceso de desarrollo económico y demográfico que permitiría que Valencia en el siglo XV superara al resto de capitales de la Corona.

Muchos han sido los estudios a la hora de calibrar las necesidades de la población urbana $^{15}$. Una cuestión que aumenta en relieve por cuanto en un conflicto bélico era primordial mantener el orden público interno y ello no era posible sin garantizar que la mayoría de la población tuviera acceso a la alimentación a precios razonables. Por todo ello es fundamental averiguar con cuánta población contaba la ciudad en esos momentos.

Para el caso de la capital podemos realizar estimaciones gracias a que poseemos las cifras de los morabatines de 1355 y 1366. Estos morabatines nos dan las cifras de 6.209 fuegos en 1355 y de 6.275 en 1366, es decir, tanto antes como al final de la guerra con Castilla, por lo que supone una información de gran valor, sobre todo porque las cifras se expresan en fuegos reales, aunque sólo se gravó a los titulares de patrimonios superiores a 105 $\mathrm{Ss}^{16}$. La problemática también radica en la estimación media de cada fuego a la hora de

\footnotetext{
14 Manuel SÁNChez Martínez, “Guerra y avituallamiento...”, pp. 523-549. No podemos evitar interrogarnos sobre cómo eran las redes de abastecimiento de los asediadores castellanos y hasta qué punto pudieron abastecerse de la huerta valenciana, aunque no poseemos documentación que nos permita resolver estos interrogantes. 15 Para una visión de esta cuestión en ámbito hispánico véase María AsEnjo GonZÁLEz, "Demografía: el factor humano en las ciudades castellanas y portuguesas a fines de la Edad Media", Las sociedades urbanas en la España medieval: XXIX Semana de Estudios Medievales, Estella, 15 a 19 de julio de 2002, ed. Gobierno de Navarra, Estella, 2003, pp. 97-150; Gaspart Feliu i MonTFort, "La demografía baixmedieval catalana: estat de la qüestió i propostes de futur", Revista d'Història Medieval, 10 (1999), pp. 13-44. Más centrados en la Corona de Aragón destacan los trabajos reunidos bajo el título Demografía y sociedad en la España bajomedieval: Aragón en la Edad Media: sesiones de trabajo, ed. Universidad de Zaragoza, Zargoza, 2001. Mientras que dedicado en exclusiva al reino de Aragón se publicó años después: José Ángel SeSMA MuÑoz y Carlos Laliena Corbera (coords.), La población de Aragón en la Edad Media (siglos XIII-XV): estudios de demografia histórica, ed. Leyere, Zaragoza, 2004. Cabe indicar que los trabajos sobre el siglo XIV son muy reducidos debido a la falta de fuentes o al carácter fragmentario de las mismas.

16 Enrique Cruselles Gómez, "La población de la ciudad de Valencia en los siglos XIV y XV", Revista d'Història Medieval, 10 (1999), pp. 45-84. Entre 1360 y 1390 se produjo en el reino de Valencia la transición del fuego real, realizado casa por casa, al fuego fiscal, que traducía la capacidad fiscal atribuida por
} 
obtener cifras de población total. Lo común, que no ha dejado de ser criticado, es aplicar un coeficiente de conversión de 4'5 habitantes por fuego, al tratarse de una región en la que predominaba la familia nuclear ${ }^{17}$. Así, la estimación para el año 1355 se sitúa en los 27.940 '5 habitantes y para el año 1366 en 28.237. Teniendo en cuenta las precauciones anteriores, sólo indicaremos que la población de la capital valenciana se situaría por encima de los 30.000 habitantes durante el período de la Guerra de los Dos Pedros ${ }^{18}$.

Este volumen de población nos podría sorprender por cuanto a partir de mediados del siglo XIV Valencia sufrió un período crítico en el que confluyeron fenómenos militares, hambres y brotes epidémicos. Una trilogía apocalíptica que no impidió que la ciudad siguiera creciendo a costa de las áreas limítrofes gracias a la corriente migratoria que hacia ella se dirigía ${ }^{19}$.

A la hora de comprender la problemática del abastecimiento urbano hay que tener en cuenta el papel de primer orden que el cereal, especialmente el trigo, jugó como base de la alimentación en época medieval, relevancia que nos obliga a centrar nuestra atención en él, puesto que también centró la de los munícipes valencianos ${ }^{20}$.

el poder público a la localidad. También hay que tener en cuenta que la tasación de fuegos era en muchas ocasiones un procedimiento sujeto a la negociación y el consenso, lo que viene a ocultar serias disfunciones del sistema fiscal. Para la cuestión del monedaje o morabatín véase Josiah C. Russell, "The medieval monedatge of Aragon and Valencia", Proceedings of the Philosophical Society, 106 (1962), pp. 403-504. Para tener una vision más complete de la demografía del reino de Valencia, específicamente de su parte norte y de su parte sur, destacan los siguientes trabajos: Enric Guinot RodRíGuEz, "Demografía medieval del nord del País Valencià", Estudis sobre la població del País Valencià: actes de les I Jornades d'Estudi sobre la població del País Valencià, València-Alacant, 20-22 de març de 1986, Carmen Pérez Aparicio (dir.), ed. Alfons el Magnànim y Institució Valenciana d'Estudis i Investigació, vol. 1, Valencia, 1988, pp. 229-249; José Ramón Hinojosa Montalvo, "Demografía y poblamiento en Alicante durante la Baja Edad Media: siglos XIII-XV", Estudios de Historia Medival. Homenaje a Luis Suárez, Miguel Ángel Ladero Quesada, Vicente Ángel Álvarez Palenzuela y Julio Valdeón Baruque (coords.), ed. Universidad de Valladolid, Valladolid, 1991, pp. 267-282.

17 Francisco Roca Traver, "Cuestiones de demografía medieval”, Hispania, 50 (1953), pp. 3-36. No hay que olvidar que este coeficiente ha sido diseñado por estudiosos de la época moderna y aplicado a realidades que no tienen por qué ser las mismas, sobre todo después de las alteraciones en el modelo demográfico que supuso la Peste Negra, con un aumento de la mortalidad infantil, pero también de la natalidad al reducirse la edad de acceso al matrimonio, sobre todo en el caso de las mujeres. A estas precauciones hay que añadir la certeza de que ciertos grupos de población no eran registrados, nos referimos a aprendices, esclavos, servicio doméstico, eclesiásticos, así como a un sector marginal de la sociedad, constituido no sólo por pobres y delincuentes, sino también de una población flotante que residía en la ciudad sin llegar a integrarse.

18 Esta estimación se aproxima a las propuestas de otros autores, como Rubio Vela quien cuantificó la población de la capital para estos años entre los 25.000 y los 28.000 habitantes. Agustín Rubio Vela, "La población de Valencia en la Baja Edad Media”, Hispania, 55 (1995), pp. 495-525.

19 Los ritmos de renovación de las poblaciones urbanas eran elevados, pudiendo llegar hasta tasas del 50\% de reemplazo en determinadas ciudades. Antoni Furió Diego, Història del País Valencià, ed. Tres i Quatre, Valencia, p. 193.

20 Daniel Cueves Granero, "Abastecimientos de la ciudad de Valencia durante la Edad Media", Saitabi, 12 (1962), pp. 141-167. 


\section{La política frumentaria}

Para tratar de garantizar el abastecimiento frumentario de la ciudad, así como unos precios contenidos en niveles aceptables para el grueso de la población, los Jurats desarrollaron una política interventora en el mercado a partir de diferentes vías, que no tenía el objetivo de sustituir a la iniciativa privada, que continuó siendo dominante, sino complementarla y corregir los desajustes del mercado. Una de estas vías era la compra directa de grano por parte de las autoridades municipales y a través de un síndico. Esta medida constituía la más costosa y arriesgada de todas debido a las importantes variaciones que sufría el precio del trigo, lo que explica que fuera poco usada, apenas en momentos de carestía y alza excesiva de precios. Situaciones que vemos repetidas a lo largo de la guerra y que explican que puntualmente se usara esta modalidad ${ }^{21}$. Otra medida poco usada por su carácter sumamente lesivo para el prestigio de la ciudad fue la requisa de cereales ${ }^{22}$.

Aparte de estas medidas de uso poco frecuente, y que solían aplicarse en momentos de elevada necesidad, destacan tres bastante más comunes. En primer lugar, los préstamos sin interés, consistentes en prestar a un comerciante un capital a cambio de que se comprometiera a importar una cantidad elevada y prefijada de cereal procedente de territorios normalmente extra foráneos y en un plazo determinado. Tras llevar a cabo esta operación se le daba un plazo para devolver el capital prestado. Este sistema era bastante oneroso para las arcas municipales, sobre todo si tenemos en cuenta las posibilidades de fraude, de manera que ni siquiera tenemos constancia de que se aplicara durante la guerra de Castilla, aunque sí se llegó a proponer ${ }^{23}$.

En segundo lugar, el precio de venta asegurado, en función del que el municipio prometía a un importador un precio fijo de venta por importar determinada cantidad de cereal, asumiendo el municipio el riesgo de que si el precio de mercado descendía le pagaría la diferencia, pero si era superior, la diferencia se la quedaba el municipio, cosa que raras veces pasaba puesto que se ajustaban los precios a los de mercado con tal de hacer la operación atractiva para el mercader. El importador perdía de esta manera la posibilidad de obtener mayores ganancias beneficiándose de alzas en el precio, pero se mantenía a salvo de las grandes oscilaciones propias del precio del cereal, era un riesgo

\footnotetext{
${ }^{21}$ Lo podemos ver en junio de 1357 cuando se saldó la deuda que la ciudad había contraído con Pere Eymerich y Pere Cabanyelles, a quienes había comisionado para comprar 100 cahíces de trigo (AMV, CC, J-2, fol. 33r). Más importante fue la que el mercader Ramon Deç-Grau realizó en junio de 1359, adquiriendo 2.500 cahíces, en función de un contrato tramitado con el Consell en octubre de 1358 (AMV, CC, J-4, fol. $38 \mathrm{v}$ ). Además, a finales de noviembre de 1362, la ciudad comisionó a Miquel Palomar, Pere Marrades y Nicolau de Valleriola para que en la nave de Joan Lombarda fueran a Cerdeña o Sicilia a adquirir cereal, suponemos que en cantidades importantes, puesto que el Consell eligió a tres de los principales prohombres de la ciudad (AMV, MC, A-14, m. 3, fol. 22v-23).

22 Hermenegildo Rausell Boizas, "Importación de cereales mediante "Ajudes" en la Valencia del primer cuarto del siglo XV", Estudis, 2 (1973), pp. 15-34.

23 Nos referimos a la propuesta que un grupo de mercaderes realizó al Consell en la sesión del 8 de julio de 1362, proponiendo importar 3.000 cahíces de trigo si la ciudad les prestaba 1.000 libras. Desconocemos si se llegó a aceptar; AMV, MC, A-14, m. 3, fol. 7v-8v.
} 
que asumía el municipio. Un riesgo que estuvo dispuesto a asumir en la etapa final de la guerra, tras haber superado dos duros asedios que agotaron las reservas de la ciudad ${ }^{24}$. Por último, el sistema de ajudes por importar cereal que se vendería en el almudín. Se trataba de un sistema de subvenciones a la importación, prometiendo pagar determinada cantidad por cahíz importado, en nuestro caso generalmente 2 ss. ${ }^{25}$, y en función de un contrato previo entre los Jurats y el importador, un "contracte d'assegurament" o "seguretat"26. En él se indicaba la subvención, la cantidad y tipo de cereal que debería importar, el plazo de tiempo para su cumplimiento y, en ocasiones, la procedencia, aunque generalmente se establecía que procediera de fuera del reino ${ }^{27}$.

El sistema de subvenciones fue el más usado por el municipio valenciano durante la guerra con Castilla. Debido a ello nos centraremos fundamentalmente en esta modalidad al constituir nuestra mejor fuente a la hora de calibrar la importancia de la política de abastecimiento municipal de trigo y el costo que supuso para la hacienda local, puesto que suele ser presentada como el segundo expediente más oneroso para las arcas públicas.

Resulta muy complicado estimar el volumen de trigo que requería la población urbana, aspecto que excede nuestros propósitos porque las fuentes no nos permiten realizar un balance, pero sí que daremos algunas referencias que pueden resultar indicativas. J. Guiral estima que para abastecer a la población de la capital valenciana eran necesarios 106.846 cahíces de trigo al año, eso sí refiriéndonos a principios del siglo XV, cuando Valencia superaría los 30.000 habitantes de manera holgada ${ }^{28}$. Una cifra que García Marsilla compara con los 109.500 cahíces que calculaba el capellán de Alfonso el Magnánimo para la ciudad de Valencia a mediados del siglo $\mathrm{XV}^{29}$. Muchos han sido los cálculos

24 Se trata de una operación que sólo se realizó una vez, en junio de 1364, cuando el Consell negoció con el mercader barcelonés Guillem Almugàver la importación de 10.000 cahíces de trigo asegurándole un precio de venta de 44 ss. por cahíz; AMV, MC, A-14, m. 6, fol. 20 (21/06/1364).

25 Esta subvención se estableció el 5 de junio de 1358 (AMV, MC, A-13, m. 3, fols. 4-6r), pero sabemos que ya se aplicaba desde antes, aunque los encargados de negociar las subvenciones eran los Jurats y podían acordar subvenciones de diferente índole y cantidad y no tenían que ceñirse estrictamente a los dos sueldos decretados.

26 Hermenegildo Rausell Boizas, "Importación de cereales...”, pp. 15-34. Esta tipología exigía que el cereal fuera importado por mar y, por ende, en barcos. Junto a ella, las ajudes de menut, consistentes en la subvención de cereal importado por tierra, "a coll de besties", recurso sólo aplicado en momentos de elevada necesidad y que implicaba la ausencia de contrato previo. Esta modalidad se testimonia sobre todo en el siglo XV, mientras que no se aplicó durante la guerra con Castilla.

27 Juan Vicente García Marsilla, La jerarquía de la mesa. Los sistemas alimentarios en la Valencia bajomedieval, ed. Diputació de València, Valencia, 1993, pp. 46-47. Cuando el comerciante incumplía el contrato de importación, tenía que hacer frente a una multa equivalente al doble de la subvención prometida. Aun así, pocas veces se aplicaron penalizaciones a los importadores, puesto que los mercaderes dedicados a la importación de trigo eran pocos y la ciudad dependía de ellos, por lo que el trato tendía a ser un tanto indulgente. Agustín RuBio Vela, "Valencia y el control de la producción cerealista del Reino en la Baja Edad Media: orígenes y planteamiento de un conflicto", Demografia y sociedad en la España bajomedieval: Aragón en la Edad Media: sesiones de trabajo, ed. Universidad de Zaragoza, Zaragoza, 2001, pp. 33-65.

28 Jaqueline Guiral-Hadziossif, Valencia, puerto mediterráneo en el siglo XV (1410-1525), ed. Alfons el Magnànim, Valencia, 1989, p. 327.

29 Juan Vicente García Marsilla, La jerarquía de la mesa.., p. 26. 
sobre los valores medios de la cantidad de cereal que necesitaría una persona al día y al año para tratar de obtener certezas sobre las necesidades del abastecimiento urbano, pero nosotros no nos detendremos en estas cuestiones que desbordan los objetivos de este trabajo, tan sólo buscamos destacar cuáles podrían haber sido las necesidades de la ciudad durante la guerra de los Dos Pedros, si bien las cifras debieron ser menores que las propuestas por Guiral y el capellán de Alfonso el Magnánimo porque la población valenciana era menos numerosa ${ }^{30}$.

Realizada esta pequeña aclaración, resulta más ilustrativo observar las cifras de las importaciones subvencionadas. Desde julio de 1356 hasta diciembre de 1357 la ciudad subvencionó la importación de 13.880 '5 cahíces, 5 fanegas y 131 barcellas de trigo, además de 6 cahíces de harina, teniendo un coste de 28.455 ss. 11 drs. En el año de 1358 se registra la importación de 24.954 ' 5 cahíces, 39 fanegas y 223 barcellas de trigo, además de 19'5 cahíces de mestall (mezcla de diferentes tipos de cereal), suponiendo una inversión de 47.463 ss. 3 drs. Por su parte, el año 1359 nos marca un considerable descenso, registrándose tan sólo $12.058^{\prime} 5$ cahíces y 32 barcellas de trigo, una subvención que costó al municipio 24.952 ss. Un descenso que se debe a unos registros incompletos que tan sólo abarcan hasta junio de 1359 , pero ese medio año nos marca una tendencia que seguramente igualaría a la del año previo. Por parte de los siguientes años, no se conservan registros para los años de 1363, 1364 y 1365, mientras que los registros de los años 1360, 1361 y 1362 dan escasa información y entre los tres tan sólo reflejan la importación de 23.071 cahíces y 28 barcellas de trigo, habiendo tenido que invertir para ello $33.033 \mathrm{ss} .8 \mathrm{drs}^{31}$. Desconocemos si la situación de estos tres años se debe a la parcialidad de las fuentes o a que apenas se puso en práctica esta política de subvenciones, lo que parece poco probable, pues las referencias de los Jurats a las necesidades de la ciudad son continuas, así como las medidas tomadas en esta materia, como más adelante veremos. Por parte de los años de 1357, 1358 y 1359, fueron años de carestía debido a las malas cosechas y las plagas.

\footnotetext{
30 Queremos destacar por su rigurosidad el cálculo realizado por P. Iradiel para el colegio español de Bolonia, estimando el consumo de pan por persona y día entre 944 y 1.536 gramos. Paulino IRAdiel Murugarren, "Estructuras de producción y de consumo de productos agrarios en los siglos XIV y XV. El modelo del Colegio Español de Bolonia", Studia Albornotiana, XXXV (1979), pp. 431-468. Para el caso de Valencia, García Marsilla estima que cada habitante consumiría entre 1'5 y 1'9 litros de trigo o, lo que es lo mismo, entre 776 y 1.000 gramos de pan; Juan Vicente García Marsilla, La jerarquía de la mesa ..., pp. 24-30. También en ámbito hispánico Martínez García calculó en 600 gramos de pan el consumo diario por persona en los hospitales de Burgos; Luis Martínez García, "La asistencia material en los hospitales de Burgos a finales de la Edad Media", Manger et boire au Moyen Âge. Actes du colloque de Nice (15-17 octubre 1982), Denis Menjot (coord.), ed. Publications de la Faculté des Lettres et des Sciences Humaines de Nice, Niza, 1984, pp. 349-369.

31 La información que ofrecemos y con la que se han elaborado las tablas procede de los Manuals d'Albarans de la Claveria Comuna del AMV, en concreto los cuadernos J-2, J-3, J-4, J-5 y J-6. Las tablas están expuestas en la página 16. Las equivalencias en litros de los diferentes tipos de medidas empleadas han sido indicadas en la nota número 49. El gran incremento que se experimentó en el año 1358 se puede deber en parte a la visita de los reyes a la ciudad, hecho que aumentaría las necesidades de trigo, trigo de calidad.
} 


\subsection{Las plagas}

En los primeros años de la guerra de los Dos Pedros la población valenciana sufrió una sucesión de malas cosechas a las que se unió una plaga de langosta, y tan sólo habían pasado 9 años de la gran peste de 1348. Tenemos noticia de que la plaga de langosta irrumpió en Barcelona en julio de 1357, aunque no provocó alarma entonces en Valencia, quizás porque fuera poco relevante ${ }^{32}$. Sí lo hizo en 1358, cuando el Consell decidió organizar una procesión para rogar que esa plaga dejara de azotar la ciudad y su huerta ${ }^{33}$. La plaga siguió siendo motivo de preocupación durante el resto de la primavera y reapareció en $1359^{34}$.

Las manifestaciones colectivas de piedad solían ser el recurso más característico de la época ante las catástrofes naturales, pero no eran el único recurso al alcance de los Jurats. Una medida común era la de movilizar a los varones de manera forzosa para combatir la plaga, como hizo el Consell en 1358, agrupando a los hombres en grupos de 50 para coger y destruir las langostas que encontraran en el campo, e imponiendo una multa de 4 drs. a quienes no quisieran ir ${ }^{35}$. Pero los hombres de la ciudad no solamente iban movidos por la amenaza de multas, pues el obispo ordenó distribuir entre ellos 500 ss., repartidos a razón de 2 drs. por almud que llenaran con los restos de las langostas muertas ${ }^{36}$. Estas medidas se repetirían en 1408 y en 1409, aunque desconocemos su grado de efectividad ${ }^{37}$. Más allá de plantear la ruina de las cosechas y la consecuente carestía, es difícil calibrar la incidencia económica de este tipo de plaga, aunque algunos la han comparado con los efectos de las sequías, provocando situaciones de grave desabastecimiento. No tenemos constancia documental de que la plaga que en 1357 afectaba a Barcelona también estuviera presente en Valencia, aunque sí sabemos que en junio existía una situación de carestía y se impulsaron las subvenciones a la importación ${ }^{38}$. Unas importaciones que aumentaron ante las consecuencias de la plaga de 1358, de cuya existencia tenemos total seguridad. Un gasto adicional que obligó a aumentar los impuestos sobre el consumo ${ }^{39}$. No obstante, en 1359, tras haberse detectado la plaga de nuevo en la Huerta de Valencia, el Consell ordenó el cese de las subvenciones a la importación de trigo argumentando que existía una gran abundancia de cereales en el término de la ciudad ${ }^{40}$. Unas subven-

\footnotetext{
32 Agustín Rubio Vela, "Presencia de la langosta. Plagas en la Valencia bajomedieval", Saitabi, 47 (1997), pp. 269-288.

33 AMV, MC, A-13, m. 4, fol. 55 (14/03/1358).

34 AMV, MC, A-13, m. 6, fol. 60r (10/04/1359).

5 AMV, MC, A-13, m. 4, fol. 65v (18/04/1358).

36 AMV, CC, J-3, fol. 55r (15/05/1358). El promotor de esta medida fue el obispo Vidal de Blanes (13561369), aunque un mes antes ya la había puesto en marcha la ciudad (AMV, CC, J-3, fol. 44r).

37 Agustín Rubio Vela, "Presencia de la langosta...”, pp. 269-288.

38 AMV, MC, A-13, m. 3, fol. 6r (03/06/1357).

39 AMV, MC, A-13, m. 5, fol. 4v (05/06/1358). Claude Guy MaUbert y Robert Vernet, "Sur les problèmes du ravitaillement dans les pays catalans. Le mouvement des céréals entre la Catalogne et le royaume de Valence pendant l'hiver 1357-1358", Cuadernos de Historia Económica de Cataluña, 12 (1974), pp. 9-24. 40 AMV, MC, A-13, m. 3, fol. 69 (24/05/1359).
} 
ciones que se reactivarían un mes más tarde, pero no a causa de la langosta, sino del temor que provocaba en los munícipes la posibilidad de que el rey de Castilla dirigiera contra la ciudad la gran armada que había preparado ese año ${ }^{41}$.

\subsection{El carácter de las importaciones frumentarias}

No es posible determinar el ritmo de las importaciones de cereal solamente a partir de la política de subvenciones. De hecho, el municipio jamás llegó a sustituir a los particulares en la tarea de abastecer la ciudad, tan sólo complementaba su esfuerzo en momentos en los que se preveía penuria ${ }^{42}$. Además, no era la única institución pública que intervenía en el mercado frumentario, también fueron comunes las medidas aplicadas por el Baile General o el propio Gobernador o su lugarteniente. De hecho, tenemos constancia de ello gracias a las veces que los Jurats informaban a estas figuras de que determinados mercaderes, que habían concertado con ellos seguretats, depositaban trigo en el almudín (puesto que su gestión era municipal) ${ }^{43}$.

Estas operaciones por parte de oficiales reales fueron bastante numerosas, aunque no tuvieron el calibre de la política de subvenciones municipal, y se agruparon todas en los años de 1358 y 1359 , al menos las que tenemos constancia, por lo que seguramente esta intervención debía estar motivada por una situación de carestía bastante preocupante. Una intervención que en ocasiones produjo importantes conflictos. En este caso, una vez superado el segundo asedio, el obispo de Tortosa, Jaume de Prades i de Foix (1362-1369), como Lugarteniente General incautó el dinero que el municipio destinaba al pago de las ajudes y procedió a administrarlo ${ }^{44}$. El conflicto residía en la prelación a la hora de pagar estas subvenciones, pues normalmente los oficiales reales tendían a anteponer a aquéllos que importaban grano procedente del reino o de los territorios de la Corona, entendiendo los territorios hispánicos de la misma. Actitud diametralmente opuesta a la de los Jurats, quienes promovían la llegada de cereales de lugares más lejanos. La protesta del Consell no se hizo esperar ante lo que consideraba una intromisión inaceptable que atentaba contra sus privilegios y, finalmente, el obispo tuvo que ceder y restituir al clavario de la ciudad, Miquel Palomar, la administración de ese capital ${ }^{45}$. Este conflicto nos sitúa ante una cuestión fundamental, ¿de dónde se abastecía la ciudad? Podemos lograr una aproximación a partir de los datos aportados por las seguretats abonadas por la ciudad, aunque limitándonos hasta el año 1359, puesto que los registros de los años de 1360-1362 apenas indican la procedencia del trigo importado, mientras que

${ }^{41}$ Agustín Rubio Vela, "Presencia de la langosta...”, pp. 269-288.

42 Hermenegildo Rausell Boizas, "Importación de cereales...", pp. 15-34.

43 Lo vemos por ejemplo en AMV, CC, J-3, fol. 44r (06/04/1358); AMV, CC, J-3, fol. 48r (19/04/1358); AMV, CC, J-3, fol. 51v (02/05/1358); AMV, CC, J-3, fol. 53r (08/05/1358); AMV, CC, J-3, fol. 54v (15/05/1358); AMV, CC, J-4, fol. 36r (26/04/1359); etc.

44 AMV, MC, A-14, m. 6, fol. 32 (04/09/1364).

45 AMV, MC, A-14, m. 6, fols. 34v-35r (08/09/1364). 
los años previos son más exactos, aún reflejando un importante porcentaje, el segundo en importancia siempre, de cargamentos en los que no se indica la procedencia exacta ${ }^{46}$. Así, para el período de julio de 1356 hasta diciembre de 1357, las principales importaciones procedieron de Cataluña (40’76\%) y Languedoc-Provenza (20'73\%), mientras que el porcentaje de trigo sin lugar específico de procedencia supuso un $24,43 \%$. El año 1358 nos marca un importante cambio: aumentaron considerablemente las subvenciones hasta superar los cinco millones de litros importados y Cerdeña (37'44\%) superó a Cataluña (19'18\%) como principal zona abastecedora, seguidas por LanguedocProvenza (15'34\%). Una tendencia que se acentuó al año siguiente, a pesar de que los registros sólo abarquen la mitad del año. En 1359 Cerdeña alcanzó el 42’03\% del trigo subvencionado, seguida a mucha distancia por Languedoc-Provenza (11\%) y Cataluña (4’92\%). Eso sí, en ambos años el porcentaje de trigo sin indicación de procedencia fue elevado, del $21^{\prime} 58 \%$ y del $41^{\prime} 75 \%$ respectivamente.

Esta alteración tiene su explicación en las guerras mantenidas por la Corona, en este caso con Génova y la revuelta sarda, que impidieron recurrir al granero sardo hasta que se firmó la paz con Génova.

\section{Procedencia del trigo subvencionado (1356-1359)}

1356-1357 (Total: 2.792.342,25 litros)

\begin{tabular}{|c|c|c|c|c|c|c|c|c|}
\hline Procedencia & Cataluña & $\begin{array}{c}\text { Sin } \\
\text { especificar }\end{array}$ & $\begin{array}{c}\text { Languedoc- } \\
\text { Provenza }\end{array}$ & Tortosa & Menorca & $\begin{array}{c}\text { Reino de } \\
\text { Valencia }\end{array}$ & Cerdeña & Italia \\
\hline Litros & $1.138 .212,75$ & $682.445,25$ & $578.863,25$ & $149.326,25$ & $105.290,5$ & $58.641,75$ & 55.878 & $3.919,5$ \\
\hline Porcentaje & $40^{\prime} 76^{\prime} \%$ & $24^{\prime} 43 \%$ & $20^{\prime} 73 \%$ & $5^{\prime} 34 \%$ & $3^{\prime} 77 \%$ & $2^{\prime} 10 \%$ & $2 \%$ & $0^{\prime} 14 \%$ \\
\hline
\end{tabular}

1358 (Total: $5.020 .896,25$ l.)

\begin{tabular}{|c|c|c|c|c|c|c|c|c|}
\hline Procedencia & Cerdeña & $\begin{array}{c}\text { Sin } \\
\text { especificar }\end{array}$ & Cataluña & $\begin{array}{c}\text { Languedoc- } \\
\text { Provenza }\end{array}$ & Tortosa & Castilla & $\begin{array}{c}\text { Reino de } \\
\text { Valencia }\end{array}$ & $\begin{array}{c}\text { Reino de } \\
\text { Mallorca }\end{array}$ \\
\hline Litros & $1.880 .254,5$ & $1.083 .674,75$ & $963.091,5$ & $770.315,75$ & $243.377,5$ & 33.366 & $26.046,25$ & 17.487 \\
\hline Porcen-taje & $37^{\prime} 44 \%$ & $21^{\prime} 58 \%$ & $19^{\prime} 18 \%$ & $15^{\prime} 34 \%$ & $4^{\prime} 84 \%$ & $0^{\prime} 66 \%$ & $0^{\prime} 51 \%$ & $0^{\prime} 34 \%$ \\
\hline
\end{tabular}

1359 (Total: 2.424.294,5 l.)

\begin{tabular}{|c|c|c|c|c|c|}
\hline Procedencia & Cerdeña & Sin especificar & $\begin{array}{c}\text { Languedoc- } \\
\text { Provenza }\end{array}$ & Cataluña & Tortosa \\
\hline Litros & $1.018 .969,5$ & 1.012 .303 & $266.676,75$ & $119.310,25$ & 7.035 \\
\hline Porcentaje & $42^{\prime} 03 \%$ & $41^{\prime} 75 \%$ & $11 \%$ & $4^{\prime} 92 \%$ & $0^{\prime} 29 \%$ \\
\hline
\end{tabular}

46 Los anteriores datos presentados en cahíces (201 litros), fanegas (33’5 1.) y barcellas (16’75 1.) han sido convertidos en litros para poder realizar estimaciones de mayor exactitud. Para ello se ha empleado la tabla de equivalencias de pesos y medidas de la Valencia medieval aportada por Francisco Sevillano Colom (1957): Valencia urbana a través del oficio de Mustaçaf, ed. Institución Alfonso el Magnánimo, Valencia, 1957, p. 65. 
Nos encontramos en los inicios de una evolución, de la conformación de un sistema frumentario que alcanzaría su plena definición en el siglo XV. De hecho, si comparamos estos porcentajes con los valores medios del siglo XV, nos damos cuenta de la importante mutación que sufriría el abastecimiento urbano. Para el siglo XV los principales lugares de procedencia del trigo que subvencionaba la ciudad fueron: Sicilia (29'43\%), el propio reino de Valencia (14'66\%), Andalucía Occidental (13’23\%), Aragón (10’13\%) y Castilla (5'41\%). El porcentaje restante, un $27^{\prime} 40 \%$, procedía de un conglomerado de diferentes regiones ${ }^{47}$. Vemos así como Cerdeña, Cataluña y Languedoc-Provenza, fundamentales para el abastecimiento en nuestro período, al llegar al siglo XV han perdido su primacía y pocas veces aparecen aportando cantidades importantes.

En nuestros registros hemos decidido individualizar Tortosa respecto al resto de Cataluña en razón a que Tortosa constituía el puerto de salida del cereal aragonés y de las comarcas del Ebro. Esto nos obliga a tratar el tema del trigo aragonés y a destacar que los datos procedentes de las subvenciones son insuficientes a la hora de determinar de dónde se abastecía la ciudad ${ }^{48}$.

Desde siempre se ha puesto de relieve que una cantidad importante de la producción triguera aragonesa llegaba a Valencia y constituía un porcentaje considerable del grano consumido en la capital valenciana. Sobre todo se ha estudiado la importación del trigo de las comarcas del Ebro a través de Tortosa y por vía marítima en barcos catalanes ${ }^{49}$. Sin embargo, la mayor parte del trigo aragonés, y también castellano, llegaba a Valencia por vía terrestre, a "coll de besties", directamente desde las zonas rurales de producción. Los protagonistas de este comercio eran pequeños mercaderes y los propios campesinos que cultivaban el trigo y otros cereales, y que a veces también los transportaban ${ }^{50}$.

47 Hermenegildo Rausell Boizas, Daniel Guillot Valls, Mateu Llop Català y Vicent Ernest Belenguer CeBrià, "Movimiento secular de las importaciones trigueras del siglo XV mediante las Ayudas de la ciudad de Valencia", Estudis, 2 (1973), pp. 5-12.

48 Albert Curto i Homedes, La intervenció municipal..., pp. 14-34. Queda por despejar la incógnita del trigo procedente de Berbería, considerado importante para el abastecimiento de la ciudad, pero los registros de nuestro período apenas indican la llegada de trigo africano, aunque sospechamos que parte del porcentaje del trigo indicado sin referencia geográfica correspondería a esta tipología, considerada de menor calidad por los contemporáneos (razón por la que posiblemente no solía recibir subvención).

49 María Luisa Ledesma Rubio y María Isabel Falcón Pérez, Zaragoza en la Baja Edad Media, ed. Librería General, Zaragoza, 1977, p. 176.

50 Estos pequeños comerciantes especializados en el comercio frumentario de escaso alcance y menor volumen, generalmente realizado por tierra, eran denominados formenters, frente a los grandes comerciantes dedicados a la importación cerealística por mar desde lugares lejanos y en gran volumen, entre otras actividades, denominados simplemente mercaders; Mario DeL TREPPO, Els mercaders catalans i l'expansió de la Corona catalano-aragonesa al segle XV, ed. Curial, Barcelona, 1976, p. 126. Durante le guerra con Castilla se repitieron las órdenes prohibiendo la exportación de grano de regiones directamente afectadas, como Oriola o Aragón, de las que se proveía directamente la ciudad de Valencia, aunque con cada tregua se podían suspender esas restricciones o incluso a veces se daban órdenes de exportación para auxiliar regiones en estado de emergencia, como la que sufrió Oriola durante su asedio; María Teresa Ferrer i MALlol, "Els efectes de la guerra dels dos Peres (1356-1369). Abastament e fam a la governació d'Oriola", Guerra y carestía en la Europa medieval, Pere Benito i Monclús y Antoni Riera i Melis (coords.), ed. Milenio, Lleida, 2014, pp. 129-148. Similares restricciones se aplicaron también en el reino de Mallorca, aunque la 
Valencia había ido construyendo un traspaís rural que superaba las fronteras políticas del reino y se adentraba en las comarcas rurales de Aragón y Castilla, zonas fundamentales para su abastecimiento. El trigo aragonés llegaba siguiendo diferentes vías fluviales, sobre todo el Turia a través de Ademuz y el Palancia, destacando la ciudad de Segorbe como principal lugar de paso de estos arrieros. Se trata de un comercio del que apenas ha quedado rastro documental pues no solía ser objeto de subvenciones por parte del Consell, al menos hasta 1380, cuando empezó a ser más frecuente ${ }^{51}$. Los datos registrados a partir de entonces permiten a Rubio Vela afirmar que el cereal aragonés importado por tierra normalmente representaba una cuarta parte del total, llegando en bastantes ocasiones al $50 \%$ y rebasando esta cifra en algunos años ${ }^{52}$. Es muy probable que estas conclusiones las podamos trasladar a las décadas de 1350 y 1360. Aun así, queda por calibrar la importancia del cereal valenciano, tanto de la Contribució de la ciudad como del reino, en el abastecimiento de la ciudad, aunque debió ser mayoritario.

\section{Legislar para alimentar la urbe}

Conforme la guerra avanzaba y la situación de carestía se acrecentaba y prolongaba, las medidas legisladas por los Jurats se volvieron más restrictivas y numerosas. En lo que respecta al trigo, en julio de 1356 la ciudad ya encontraba dificultades a la hora de financiar su política frumentaria, lo que obligó a los Jurats a establecer un gravamen de

elevada necesidad de grano de la ciudad de Valencia motivó que se otorgaran licencias de exportación con destino a la capital valenciana, como la que los jurats de Mallorca otorgaron a Pere Fuster en 1358; ACA, CANCILLERÍA, Registros, NÚM.1158, fols. 69v-70r (Barcelona, 14/06/1358). Con los registros actuales resulta imposible determinar cuáles fueron los efectos de estas restricciones sobre el flujo terrestre del grano aragonés con destino a Valencia, aunque es muy posible que las regiones aragonesas alejadas del frente continuaran exportando en la medida de lo posible, pero no olvidemos que la presencia de tropas implicaría un aumento del mercado regional, reduciendo por ello las necesidades de exportación; para las dificultades del comercio terrestre véase Agustín Rubio Vela, "Trigo de Aragón en la Valencia del Trescientos", Crecimiento económico y formación de los mercados en Aragón en la Edad Media (1200-1350), José Ángel Sesma Muñoz y Carlos Laliena Corbera (coords.), ed. Grupo CEMA-Universidad de Zaragoza, Zaragoza, 2009, pp. 319-368; José Ángel Sesma MuÑoz, "El comercio exterior de la Corona por vías terrestres. Un comercio intenso y fragmentado", La Corona de Aragón en el centro de su Historia. 1208-1458. Aspectos económicos y sociales, José Ángel Sesma Muñoz (coord.), ed. Grupo CEMA-Gobierno de Aragón, Zaragoza, 2010, pp. 345-362.

51 En momentos de carestía sí que se otorgaban ajudes de menut, subvenciones a la importación terrestre de cereal, aunque no se aplicaron durante nuestro período de estudio y además se realizaban sin contrato previo. Sí que tenemos constancia de que se subvencionó en 1351-1352 la importación de trigo desde Villel, aldea de Teruel. En otras ocasiones se recurrió a la compra directa de trigo aragonés, como en 1352 y en 1356; Agustín Rubio Vela, "Valencia y los aragoneses en la Baja Edad Media: la ruta del trigo", Caplletra, 32 (2002), pp. 95-110.

52 Ibídem. Hay que tener en cuenta el gran número de acémilas que serían necesarias para articular este comercio, pues tan sólo para transportar cien cahíces era necesario más de cien bestias de carga, mientras que una gran embarcación como la nau, en el Mediterráneo de mediados del siglo XIV, podía transportar 4.000 cahíces; Arcadi García Sanz y Núria Coll Juliè, Galeres mercants catalanes dels segles XIV i XV, ed. Pagès editors, Barcelona, 1994, pp. 207-254. 
1 sueldo sobre cada cahíz de trigo que se depositara en el almudín ${ }^{53}$. Una medida que afectaba a los importadores, en primera instancia, pero repercutía al final en el precio de venta, encareciendo el producto.

Además, la necesidad de financiar las ajudes llevó a que finalmente se estableciera una sisa de 2 ss. por cada cahíz de trigo vendido en el almudín, medida necesaria por cuanto la ciudad adeudaba ya 1.000 libras en el pago de subvenciones ${ }^{54}$. Se hacía recaer así directamente sobre el consumidor el coste de la política de subvenciones, de manera que hay que matizar la idea consistente en considerar a esta política como una de las dos principales causas del endeudamiento municipal, puesto que a partir de determinado momento se hizo recaer su peso directamente sobre el consumidor.

Detengámonos por un instante para calibrar mejor las consecuencias de estas medidas, que se pueden resumir en una sola: incentivaron el fraude. Así lo ponían de relieve los Jurats tras un período de tiempo en que habían podido ver aplicadas sus medidas: la gente intentaba adquirir cereal fuera del almudín con tal de evitar el pago de esos dos sueldos, así como otras cargas ${ }^{55}$. Los munícipes trataron de combatir esto aumentando las multas, de hasta $60 \mathrm{ss}$. por cada vez que se infringiera la prohibición de comprar cereal fuera del almudín, un propósito cuanto menos infructuoso, por más que hicieran equivaler la multa por este delito a la que se pagaba en caso de exportar cereales del reino sin permiso ${ }^{56}$.

El conflicto evidencia que los precios pagados fuera del almudín podían llegar a ser menores, porque en caso contrario no se correría el riesgo de las sanciones. ¿Acaso no se subvencionaba la importación de cereal para evitar la subida de los precios? Ahora era el municipio el responsable de la subida de los precios a causa de sus excesivos gravámenes. Unos gravámenes que recaían tanto sobre los cahíces importados de manera subvencionada como sobre los que no, pero todos se tenían que vender a través del almudín. En definitiva, la ciudad había acabado convirtiendo la política frumentaria en una fuente de ingresos. Esta expresión, "fuente de ingresos", no nos puede llevar a engaño, nos referimos a que el municipio acabó poniendo la política frumentaria al servicio de la deuda, derivando hacia ella los recursos en principio destinados a garantizar el abastecimiento urbano, que no fue desatendido, de manera que esto se operó aumentando los gravámenes sobre el cereal y argumentando el coste de la política frumentaria. Entonces, ¿cuál era el precio de venta del cereal, su precio de mercado? Es difícil de conocer por cuanto el cereal era un producto sujeto a enormes variaciones estacionales y no existen estudios sobre nuestro período ${ }^{57}$. Por suerte, la documentación municipal

53 AMV, MC, A-13, m. 1, fol. 9 (16/07/1356).

54 AMV, MC, A-13, m. 3, fols. 68v-70r (24/05/1359); AMV, MC, A-13, m. 4, fols. 22v-24r (04/09/1359).

55 Referencias a esta escalada del fraude las podemos encontrar el 27 de julio de 1358 (AMV, MC, A-13, m. 3, fols. 26-27r) y el 19 de septiembre de 1360 (AMV, MC, A-14, m. 1, fols. 10v-12r ).

56 AMV, MC, A-13, m. 3, fols. 26-27r (27/07/1358).

57 Para finales del siglo XIV destaca el trabajo de A. J. Mira Jódar, quien nos ofrece las siguientes cifras para el caso de Alcoi: en 1378 el cahíz de trigo costaba 26 ss., en 1379 su coste se situaba en 34 ss. y al año siguiente alcanzaba los 40 ss. Se pone así de relieve las enormes variaciones y las alzas que podía sufrir 
ha conservado unas pocas referencias que quizás arrojen luz sobre el particular. En mayo de 1359 la ciudad compraba a Ramon Deç-Grau 2.500 cahíces de trigo, pagándole 33 ss. por cahíz ${ }^{58}$. Tratándose de una compra directa, es muy posible que este precio refleje de manera bastante aproximada su coste en el mercado. Años después, en junio de 1364, el mercader barcelonés Guillem Almugàver propuso al Consell importar cereal y venderlo al municipio al precio de 44 ss. por cahíz, precio que los munícipes consideraron aceptable, por lo que también deberíamos considerarlo bastante ajustado a la realidad del mercado en razón a que se trataba de operaciones que no buscaban obtener beneficios sino garantizar el abastecimiento de la ciudad y que, de hecho, no era extraño que se saldaran con pérdidas para el municipio ${ }^{59}$.

El que el precio del trigo ese año se colocara por encima de los 40 ss. por cahíz queda reflejado por la regulación de precios de cereales que en enero de 1364 promulgó el Consell y que tasaba la fanega de trigo vendida a través del almudín en 8 ss., por lo que el cahíz debería situarse en unos 48 ss. En esta regulación también se contemplaban otros cereales: el cahíz de panizo a 25 ss., el cahíz de centeno a 20 ss., el de avena a 20 ss. y el de cebada a 24 ss. No podemos pasar por alto la datación del documento, el 29 de enero de 1364, meses antes del segundo asedio castellano; de hecho, en esa misma normativa se prohibía que quien tuviera provisiones de cereal suficientes para dos meses pudiera comprar más, una medida dirigida contra los acaparadores en una ciudad cercada ${ }^{60}$.

Toda esta política no dejó de provocar tensiones. Si en un principio la Corona se había posicionado al lado de los productores y permitía la libre exportación de cereales del reino, a partir de 1329 la situación cambió, Alfonso el Benigno prohibió la exportación y, además, los Jurats de la capital obtuvieron la potestad de velar por su cumplimiento, pudiendo armar embarcaciones con tal de vigilar las costas y evitar la exportación ilegal ${ }^{61}$. Una potestad que el municipio ejerció con asiduidad durante la guerra ${ }^{62}$,

este producto; Antonio José MiRa JóDAR, Fiscalidad real y finanzas municipales. Las bailías reales del sur del País Valenciano a finales de la Edad Media (1378-1530), Tesis Doctoral (dir. A. Furió), Universitat de València, València, 1994, p. 534. De manera contemporánea a la guerra, A. Furió nos proporciona datos del precio del cahíz de cereal en el reino de Valencia, pero no del trigo, sino de la cebada (30-33 ss. en 1364 y $18-20$ ss. en 1366) y del panizo y avena (28 ss. en 1366); Antoni Furió Diego, "Disettes et famines en temps de croissance. Une Révision de la "Crise de 1300": le royaume de Valence dans la première moitié du XIV siècle", Les disettes dans la conjoncture de 1300 en Méditerranée Occidentale, Monique Bourin, John Drendel y François Menant (coords.), ed. École Française de Rome, Roma, 2011, pp. 343-416.

58 AMV, CC, J-4, fol. 38v.

59 AMV, MC, A-14, m. 6, fol. 20 (21/06/1364).

60 AMV, MC, A-14, m. 5, fols. 4-5.

${ }^{61}$ Agustín Rubio Vela, "El abastecimiento cerealista de una gran urbe bajomedieval. Aproximación al problema campo-ciudad en el País Valenciano", L'Escenari històric del Xúquer. Actes de la IV Assemblea de la Ribera, ed. Ajuntament de L'Alcudia, L'Alcúdia, 1986, pp. 102-135.

${ }^{62}$ Nosotros podemos ver cómo la ciudad de Valencia armó naves con este fin en los siguientes documentos: AMV, CC, J-2, fol. 28v (01/05/1357); AMV, CC, J-5, fol. 7r (03/10/1360); M.C. A-13, m. 1, fols. 5-8r (27/07/1356); AMV, CC, J-5, fol. 9r (19/11/1360). 
además de aumentar las penas y multas, que generalmente se situaron en los $60 \mathrm{ss} .{ }^{63}$. Por supuesto, la zona más conflictiva era la del sur, debido a que era la principal zona excedentaria en el reino.

Era común que en ocasiones de gran carestía las ciudades mediterráneas recurrieran a la fuerza, apresando naves cargadas de cereal o coaccionándolas para que llegaran a sus puertos $^{64}$. Los conflictos se producían incluso entre ciudades de la propia Corona, como los que salpicaron los años de 1410-1412, aunque desconocemos si durante la guerra con Castilla se produjo este tipo de conflictos. Sí que se emplearon otras medidas de coacción, pero de manera más local, por ejemplo, enviando comisiones que recorrían el término de la ciudad para forzar a llevar los cereales al almudín ${ }^{65}$.

Ahora bien, no bastaba con la coacción; los regidores municipales lo sabían e impulsaron medidas complementarias a las grandes políticas de abastecimiento con tal de hacer más atractiva la importación frumentaria ${ }^{66}$. Una de estas medidas consistía en conceder permisos de exportación de arroz a cambio de importar trigo desde el exterior, normalmente una carga de arroz por cada cahíz de trigo ${ }^{67}$. O bien, se autorizaba la salida de determinados productos que tenían su salida vedada o simplemente se permitía que se cargaran mercancías (como paños) como forma de subvención, agilizando su salida ${ }^{68}$. En otras ocasiones se permitía la importación de productos que normalmente tenían la entrada vedada a la ciudad y su término, como el vino (sí que se permitía normalmente la importación de vino de gran calidad como las malvasías).

También se trató de agilizar las relaciones con los intermediarios, recurriendo a las operaciones de los corredores de negocios para conseguir que grandes mercaderes importaran grano a la ciudad. El municipio hizo uso de estos servicios en mayo de 1357, en mayo de 1358, en mayo de 1359 y en octubre de $1361^{69}$. Estas operaciones, realizadas casi siempre en mayo, consistían en dar seguretats, es decir, eran los corredores los que concertaban las subvenciones porque conocían mejor que los Jurats el mercado frumentario, y éstos recurrían a ellos cuando encontraban dificultades. La cifra récord la alcanzó Berthomeu Borrell en 1359, llegando a asegurar 5.394 cahíces de trigo con diferentes mercaderes. Una cantidad muy elevada y por la que se le retribuyó a razón de 5 ss. por cada centenar de cahíces asegurados ${ }^{70}$.

\footnotetext{
63 AMV, MC, A-13, m. 2, fol. 54r-56r (14/03/1358). También se trató de combatir el fraude en la molienda, ordenando que antes de molerlos, los granos fueran llevados al "pes de la farina" y que sólo con el albarán allí expedido pudieran ser molidos, bajo pena de 60 ss. (AMV, MC, A-13, m. 1, fols. 67-69r).

64 Juan Vicente García Marsilla, La jerarquía de la mesa...", pp. 49-52.

65 AMV, CC, J-2, fol. 5v (24/09/1356); AMV, CC, J-2, fol. 15r (03/01/1357).

66 María Teresa Ferrer i Mallol, "Els efectes de la guerra...”, pp. 179-204.

67 Juan Vicente García Marsilla, La jerarquía de la mesa..., pp. 49-57. Podemos ver esta práctica aplicada en los siguientes documentos: AMV, CC, J-3, fol. 53v (11/05/1358); AMV, CC, J-3, fol. 54r (11/05/1358); AMV, CC, J-4, fol. 7v (27/06/1358); cabe indicar que en la mayoría de las ocasiones a quien vemos realizando esta operación es el Baile General y no los Jurats.

68 AMV, CC, J-3, fol. 56v (18/05/1358).

${ }^{69}$ AMV, CC, J-2, fol. 33v (25/05/1357); AMV, CC, J-3, fol. 56v (18/05/1358); AMV, CC, J-4, fol. 36v (01/05/1359); AMV, CC, J-6, fol. 10v (26/10/1361).

70 AMV, CC, J-4, fol. 36v (01/05/1359).
} 
En ocasiones, el Consell decidía enviar a un síndico para hacer venir a la ciudad un determinado cargamento de trigo, bien para contratarlo, bien habiéndolo contratado ya. Esta operación es la que hace más patente una situación de carestía, sobre todo en la coyuntura del invierno de 1361-1362, cuando se comisionó al notario del Consell, Berenguer de Ripoll, para ir a Ibiza con tal de hacer venir la barca de Guillem Alberoni, vecino de Valencia, que estaba cargada de trigo ${ }^{71}$. Además, en diciembre de 1361, el Consell retribuía los servicios de otro notario, Berenguer de Peramola, por haber ido a Castilla con el fin de comprar ganado para la ciudad aprovechando la tregua ${ }^{72}$.

Los Jurats no siempre debieron contentarse con delegar estas operaciones en corredores y notarios, por lo que a veces trataron directamente con mercaderes foráneos, no sólo con los que se encontraban en Valencia, como acostumbraban. Así, en julio de 1357, negociaban con mercaderes barceloneses la importación de cereal, mientras que en agosto de 1358 recurrían a mercaderes de Narbona $^{73}$. De esta forma se requería la directa colaboración de comerciantes de dos grandes áreas de abastecimiento frumentario de la ciudad, Cataluña y Languedoc-Provenza, como ya habíamos podido ver.

Esto nos lleva a preguntarnos cuál era el perfil de los mercaderes que abastecían de trigo a la ciudad, ¿eran habitantes de Valencia o eran foráneos? Conocemos ya la procedencia del grano, pero no la de los mercaderes que lo importaban, aspecto que nos podría ayudar a conocer mejor las redes de comercialización. En cuanto a las fuentes, tan sólo hemos podido utilizar los registros de Claveria Comuna, Manuals d'Albaranas de los años 1356, 1357 y 1358 por ser los más rigurosos a la hora de indicar el origen de los mercaderes.

Así, para el período que abarca desde julio de 1356 hasta diciembre de 1357, de un total de 97 mercaderes que recibieron subvenciones, 29 procedían de Valencia capital, o por lo menos estaban afincados en ella, mientras que 60 eran de diferentes partes de Cataluña. Esto nos indicaría el predominio de los mercaderes catalanes, ahora bien, éstos importaron 5.890 cahíces, 2 fanegas y 89 barcellas, mientras que los valencianos, a pesar de ser poco menos de la mitad respecto a los mercaderes catalanes, fueron responsables de la importación de 4.411 cahíces y 62 barcellas. Es decir, entre los catalanes predominaban los pequeños mercaderes, lo que no quiere decir que no hubiera grandes mercaderes, como Ramon Salvador, de Barcelona, mientras que entre los valencianos el peso de los grandes mercaderes era mayor. Esto se explica por el hecho de que Cataluña era una zona exportadora muy amplia y encontramos a numerosos mercaderes que se dedicaban a exportar los productos de sus regiones más directas, predominando por ello

\footnotetext{
71 AMV, CC, J-6, fol. 20v (07/02/1362), 22v (21/02/1362), 23r (02/03/1362). Cabe indicar que el cargamento de Alberoni no fue contratado por la ciudad, recibió la orden de llevar ese trigo a Valencia de manos del propio rey, preocupado por el abastecimiento de la urbe. El que la ciudad enviara a un síndico seguramente se debiera a la tardanza de Alberoni en cumplir con su cometido; AMV, CC, J-6, fol. 24v (21/03/1362).

72 AMV, CC, J-6, fol. 14v (18/12/1361).

73 AMV, CC, J-3, fol. 6 (29/07/1357); AMV, CC, J-3, fol. 35v (08/08/1358). La ciudad volvió a recurrir a mercaderes barceloneses en octubre de 1362, cuando comisionó a Berenguer Ballester para contratar seguretats; AMV, MC, A-14, m. 3, fols. 13v-16r (17/10/1362).
} 
los pequeños cargamentos. Por parte de los valencianos, al tratarse de un negocio de importación desde lugares lejanos, sólo participaban grandes mercaderes que poseían los capitales y contactos necesarios para proveerse de cereal en zonas lejanas respecto a su base de operaciones y transportarlo en cantidades suficientes como para que fuera un negocio rentable.

En el año 1358 las importaciones subvencionadas aumentaron considerablemente y, de manera paralela, también lo hicieron los mercaderes que intervenían en este negocio. Contabilizamos 170, de los que 64 eran catalanes y 49 valencianos, mientras que los restantes 57 procedían de diferentes lugares. Los catalanes importaron 9.787 cahíces, 23 fanegas y 85 barcellas, mientras que los valencianos alcanzaron los 8.420 cahíces, 6 fanegas y 82 barcellas. La tendencia de los mercaderes valencianos se mantiene, aumentaron su número en 20 mercaderes y casi doblaron las cantidades previas. El cambio importante se produce en cuanto a los catalanes, que sólo aumentaron su número en 4 operadores, pero que casi doblaron la cantidad de trigo importado respecto a la anterior etapa. La diferencia viene marcada por la potencia de los grandes mercaderes barceloneses, una potencia que ahora podían desarrollar gracias a la paz con Génova. ¿Y esto qué tiene que ver? En 1358 Cerdeña superó a Cataluña y Languedoc-Provenza, juntas, como zona abastecedora de Valencia. Fue la paz con Génova lo que permitió que los grandes mercaderes reactivaran sus negocios en la isla, unos negocios que escapaban a los pequeños mercaderes, más limitados al ámbito regional.

Por parte de los valencianos, hay que indicar que 2 procedían de Oriola y los restantes de Valencia capital; el que no encontremos más mercaderes de otras zonas del reino se debe a que no recibían subvención, por ello la lógica nos obliga a pensar que los mercaderes procedentes del reino de Valencia fueron mayoritarios en el abastecimiento de la capital, pero esto no quedaría reflejado porque la mayoría se limitaba al ámbito regional del reino y no recibía subvención.

\subsection{Previsiones logísticas}

No podemos olvidar una cuestión fundamental, los molinos. Conocemos que al principio de la guerra, cuando todavía no se había declarado, pero todos se preparaban para ella, la ciudad construía unos "molins de sanch", o sea, unos molinos de tracción animal". Valencia era una ciudad que iniciaba un ascenso demográfico que la Peste Negra no había conseguido detener, y los Jurats no estaban dispuestos a que la guerra lo detuviera, por ello emplazaron estos molinos no junto al río o las principales acequias para aprovechar la fuerza hidráulica, sino que se rigieron por un criterio de control y seguridad, los situaron dentro de las murallas, a pesar del sobrecoste que podría suponer la tracción animal. Un sobrecoste quizás necesario por las sequías que periódicamente sufría el reino desde principios de siglo y que podían llegar a dejar inútiles los molinos hidráulicos de la ciudad.

${ }_{74}$ Lo conocemos por diversas facturas que el municipio abonó en octubre y diciembre de 1356: AMV, CC, J-2, fol. 11r (12/11/1356); AMV, CC, J-2, fol. 11v (15/11/1356); AMV, CC, J-2, fol. 12r (03/12/1356). 
El devenir histórico les dio la razón. En julio de 1362, ante la amenaza de un asedio castellano, que acabaría sufriendo la ciudad al año siguiente, los Jurats decidieron que el molino que se encontraba en el camino del mar fuera desmontado y reconstruido dentro de los muros de la ciudad ${ }^{75}$.

Todas estas medidas fueron insuficientes. Mientras los castellanos cercaban la ciudad, el hambre la invadía. Tan sólo se trataba del primer asedio y los munícipes ya eran conscientes de que sus medidas habían fracasado. Ellos argumentaron que estas medidas eran suficientes para la población de la ciudad, pero no para toda la gente que, sin habitar en ella, se refugió tras sus muros. Ante ello decidieron permitir la construcción de un nuevo molino de 4 o 5 muelas con tal de garantizar el abastecimiento de harina. Fueron Joan Doliç y Domingo Borràs quienes se hicieron con el permiso para construir este nuevo molino, que se situó en una de las acequias dentro de los muros nuevos ${ }^{76}$. Ya entonces temía el Consell que la ciudad fuera objeto de un nuevo asedio castellano, un temor que en pocos meses se materializaría.

La ciudad tuvo poco tiempo para prepararse ante este segundo asedio, es posible que el nuevo molino ni siquiera estuviera preparado. La situación de carestía debió ser especialmente dura si atendemos a las subvenciones que 10 días después de finalizar el cerco castellano decretó el municipio para importar cereal desde fuera del reino: 4 ss. por cahíz de trigo, 2 ss. por cahíz de avena o cebada, 4 ss. por cahíz de harina de trigo y 2 ss. si la harina era de cebada. Por primera vez se daba subvención a cereales que no fueran trigo y, además, el rey ordenaba que todo el grano que saliera por el puerto de Peñíscola fuera llevado a la capital ${ }^{77}$. Las medidas hablan por sí solas, la situación de desabastecimiento tras el asedio era patente en la ciudad y toda ayuda era poca para llenar el almudín. Incluso se llegó a establecer que el cahíz de arroz se vendiera dentro del almudín y al precio de 14 ss. por cahíz ${ }^{78}$.

Si estas medidas tenían lugar en mayo, un mes más tarde se ponía de relieve el mal estado de los molinos de la ciudad a pesar de todas las iniciativas que se habían aplicado para su mejora. El Consell no tuvo más remedio que comisionar a unos mercaderes para que fueran a Barcelona y Tortosa y allí molieran 1.000 cahíces de trigo para traer la harina a la ciudad, donde el municipio se la compraría para distribuirla ${ }^{79}$. Una medida

\footnotetext{
75 AMV, MC, A-14, m. 3, fols. 7v-8v (08/07/1362).

76 AMV, MC, A-14, m. 4, fols. 5-6r (07/06/1363); AMV, MC, A-14, m. 4, fols. 6v-9 (20/06/1363); El municipio estableció una serie de condiciones para la construcción de este molino, como el emplazamiento, y se comprometió a proveerles de piedra procedente del cementerio de los judíos y a construir un nuevo tramo de acequia para abastecerlo, desde el Puente del Temple, pasando por el Convento de los Predicadores hasta el Portal de la Mar, donde se uniría al brazo que abastecía el molino de "Na Jaquesa". Gracias a este último documento también conocemos que la ciudad quedó desabastecida de leña durante al asedio, pues los horneros, "forners", cocían menos el pan, una costumbre que extendieron más allá del asedio, provocando la queja de la población y la intervención del Consell, que impuso multas de 5 ss. a quienes mantuvieran esta práctica.

77 AMV, MC, A-14, m. 6, fols. 6-8r (20/05/1364).

78 AMV, MC, A-14, m. 6, fols. 13-14r (29/05/1364).

79 AMV, MC, A-14, m. 6, fol. 22 (16/06/1364).
} 
sujeta a las circunstancias, unas circunstancias que obligaron a la ciudad a contribuir con 500 cahíces de trigo al abastecimiento de Oriola, a petición del lugarteniente del rey, el obispo de Tortosa, solicitud que el rey elevaría a orden directa para abastecer Oriola con todo el grano posible ${ }^{80}$.

A pesar de las continuas menciones a la situación de desabastecimiento que sufría la ciudad y las medidas que las acompañaban durante estos meses, en octubre de 1364 nos encontramos con una situación contradictoria, en el almudín había cereal cuya importación había sido subvencionada y que no se conseguía vender. Si la ciudad no conseguía vender ese cereal se echaría a perder y, lo que es peor, no se pagarían las subvenciones a los mercaderes que habían importado ese grano, creando inseguridad y poniendo en peligro la política de subvenciones de la ciudad ${ }^{81}$.

La solución que adoptaron los Jurats tres meses más tarde consistió en repartir entre 2.500 y 3.000 cahíces de cereal entre la población, obligándola por supuesto a pagar$\operatorname{los}^{82}$. Se trataba, por tanto, de una compra forzosa, puesto que a la ciudad, antes desabastecida, ahora le sobraba el cereal. ¿Es que las políticas del Consell fueron efectivas en un grado que resultaba excesivo? No. La razón de que el cereal del almudín no se vendiera debemos buscarla en el fraude y el contrabando dentro de los muros de la propia ciudad. Un fraude impulsado por las gravosas sisas que gravaban el cereal y que habían sido establecidas al tiempo que las primas que antes indicábamos y resaltábamos por su amplitud al incorporar más cereales que el trigo y por su elevada cuantía que hacía de la importación un negocio muy atractivo para los mercaderes. En concreto, se fijó una sisa de 4 ss. por cahíz de cereal, 2 ss. por el de avena o cebada, 12 drs. por el cahíz de panizo, centeno, espelta y otros cereales menores, el cahíz de mestall pagaría según los cereales de que se compusiera; en cuanto a la harina, la arroba de harina de trigo se fijó en 4 drs., la de cebada en 2 drs. y la de panizo, centeno, espelta u otros cereales menores en 1 dinero ${ }^{83}$.

De esta forma, la política de subvenciones de la ciudad en ocasiones podía mostrarse contraproducente, por cuanto había llegado a un punto en que su costo era excesivo y, al hacer recaer su peso directamente sobre el consumidor, se le ahuyentaba de las vías legales de comercialización. Hemos podido ver cómo se acabó estableciendo una total correspondencia entre las primas a la importación y las sisas que se establecían para financiarlas, una fiscalización que aumentaba en la medida de que no eran las únicas sisas que gravaban estos productos.

\footnotetext{
80 AMV, MC, A-14, m. 6, fols. 23-24r (17/07/1364); cabe recordar que Oriola era de las pocas plazas del sur que no estaba en poder de Pedro I, quien la sitiaría a principios de diciembre; José Vicente CABEzuelo Pliego, La guerra de los Dos Pedros..., pp. 83-107.

81 AMV, MC, A-14, m. 6, fols. 38-39r (15/10/1364). Esto también nos pone de relieve cómo la política de subvenciones se hacía recaer ya directamente sobre los consumidores, hasta que no se vendiera ese cereal, no se pagarían las subvenciones a los mercaderes que lo habían importado.

82 AMV, MC, A-14, m. 6, fols. 52v-54 (17/05/1365).

83 AMV, MC, A-14, m. 6, fols. 6-8r (20/05/1364).
} 
No disponemos de registros para estudiar las vías ilegales de comercialización del grano, nunca los hubo, era un mercado al margen de la ley y no dejaba rastro documental. Aun así, nos atreveremos a lanzar una hipótesis en lo referente a su articulación dentro de los muros de la ciudad. La única forma de introducir cantidades relevantes de cereal dentro de los muros de la ciudad, sin que fueran dirigidas por las autoridades al almudín, sería por medio de los campesinos que iban a la capital a pagar sus rentas a los señores que allí residían, rentas que en muchas ocasiones cobraban en especie.

Unos señores que pertenecían a los dos colectivos que más se habían opuesto a la política frumentaria de la ciudad, el clero y la nobleza. Política intervencionista en el mercado que respondía a los intereses de los mercaderes, de los ciutadans que controlaban la institución municipal ${ }^{84}$. Así, es posible que en torno a los señores de la tierra afincados en Valencia se articularan vías alternativas de comercialización, al margen de la fiscalidad municipal, organizándose así un mercado negro del grano ${ }^{85}$.

Un mercado que pasaba de ser "libre" a "negro" a partir del momento en que el municipio imponía regulaciones demasiado restrictivas. Es en estos momentos cuando vemos a los munícipes impulsar una campaña reguladora y monopolística sobre el mercado, nunca antes vista, con la excusa de la guerra. El afán controlador llegaba hasta el punto de tratar de que aquellos habitantes que disponían de reservas frumentarias propias no vendieran sus excedentes si no era a través del almudín y con los precios tasados por el municipio.

\section{En conclusión}

Toda conclusión exige de elementos de comparación, pero es difícil encontrar casos análogos al de Valencia, o al menos similares dentro del período estudiado. La compa-

\footnotetext{
84 Diversos investigadores han estudiado esta conjunción de intereses públicos y privados en cuanto a la política intervencionista en el mercado propia del municipio, lo que explica el hecho de que en momentos de abundancia se produjeran declaraciones públicas de escasez, como podemos ver para la primera mitad del siglo XV; Enrique Cruselles Gómez, José María Cruselles Gómez y Rafael Narbona Vizcaíno, "El sistema de abastecimiento frumentario de la ciudad de Valencia en el siglo XV: entre la subvención pública y el negocio privado", La Mediterrània, àrea de convergència de sistemes alimentaris (segles V-XVIII), XIV Jornades d'Estudis Històrics Locals, ed. Institut d'Estudis Baleàrics, Palma, 1996, pp. 305-332. De manera más concreta, el Dr. Narbona ha demostrado el alto grado de identificación entre los miembros del Consell y los agentes que participaban en los negocios públicos, especialmente en las subvenciones a la importación de grano, a partir de los registros contables de la tabla de cambio de Valencia para el ejercicio 1411-1412; Rafael Narbona VizCaíno, "Cultura política y comunidad urbana: Valencia, siglos XIV-XV", Edad Media: revista de historia, 14 (2013), pp. 171-211. En el marco del presente trabajo se elaboró un listado exhaustivo con la nómina de todos los mercaderes que se beneficiaron del sistema de subvenciones durante la guerra de Castilla, mostrando las cantidades que importaron, la subvención obtenida y el lugar de procedencia del grano, pero debido a problemas de espacio no ha podido ser incluido en el presente artículo.

85 Los Jurats trataron de combatirlo exigiendo que se presentara a los molineros el albarán de compra del cereal en el almudín, en caso contrario se incautaría ese cereal; AMV, MC, A-14, m. 6, fols. 8v-11r $(24 / 05 / 1364)$.
} 
ración con ciudades del interior no es viable debido a los condicionantes y alteraciones que imponía el comercio terrestre de grano. Es necesario que nos centremos en las ciudades costeras de la Corona de Aragón, las cuales, en líneas generales, seguían el sistema de intervención municipal arriba descrito. Destaca Tortosa, que, no obstante, al tratarse de un gran centro redistribuidor gracias al flujo del Ebro, sus munícipes no tuvieron que aplicar medidas tan agresivas durante la guerra porque no tuvieron que afrontar situaciones tan graves como la de Valencia ${ }^{86}$.

Por parte de Barcelona, su poderío financiero y comercial se personificaba en una serie de grandes mercaderes y financieros, o sea, en unas redes de abastecimiento más amplias y en un sector financiero capaz de sostenerlas. Sin embargo, la situación es más similar a la de nuestro contexto un siglo después, durante la Guerra Civil Catalana (1462-1472). Durante el conflicto el Consell de Cent aplicó el sistema de intervención ya descrito, pero tras unos primeros años de intensa actividad, el sistema de intervención pública comenzó a decaer y a reducir su actividad debido a un aumento de la deuda que esa misma intervención generaba y que hacía que el sistema fuera insostenible, llegando a poner al borde de la bancarrota a la Taula de Canvi, el banco de la ciudad ${ }^{87}$. En cambio, en Valencia la guerra impulsó el sistema de intervención municipal, aumentando la deuda del municipio, pero fue una tendencia sostenible por cuanto el sector financiero se desarrolló para responder a ese reto ${ }^{88}$.

Ahora bien, ¿fue la política municipal efectiva en Valencia? La respuesta no es fácil, de hecho, nos plantea más preguntas: ¿usaron los munícipes el reparto de ayudas para reforzar sus redes clientelares? ¿estaban en el gobierno municipal algunos de los mayores acaparadores de grano de la ciudad? Por desgracia, no poseemos respuestas que despejen estos interrogantes, todavía.

Los conflictos bélicos interferían en las redes de comercialización creando una serie de desequilibrios que precisaban de una acción pública que los corrigiera. Los ejércitos castellanos llevaron a cabo tareas de tala del campo y de destrucción de las infraestructuras de abastecimiento con el propósito de mermar la capacidad de resistencia del enemigo. Y, a pesar de todo ello, la guerra no bloqueaba el funcionamiento del mercado, sino que generaba un desequilibrio que, debido al alza de los precios, dejaba

\footnotetext{
86 Albert CuRTo i Homedes, La intervenció municipal ..., pp. 69-164.

87 Pol Serrahima Balius, "Wheat provisioning in Barcelona during the Catalan Civil War (1462-1472): Markets and Public Response", Guerra y carestía en la Europa medieval, Pere Benito i Monclús y Antoni Riera i Melis (coords.), ed. Milenio, Lleida, 2014, pp. 179-204. Este autor incorpora estadísticas y datos sobre el precio del trigo adquirido por tres instituciones eclesiásticas en Barcelona durante el conflicto, aunque el siglo de diferencia que media entre ambos conflictos impide una comparación directa o que sus datos sean usados de referencia, no así la tendencia de evolución de precios descrita, similar a la descrita en este trabajo.

88 Sobre todo gracias al desarrollo del sistema censal como medida para financiar la deuda, pasando de ser casi inexistente en las finanzas municipales valencianas antes de la guerra, a mediatizarlas al final de la misma; Juan Vicente García Marsilla, Vivir a crédito en la Valencia medieval: de los orígenes del sistema censal al endeudamiento del municipio, ed. Universitat de València, Valencia, 2002.
} 
fuera de él a una parte de la población ${ }^{89}$. Su respuesta era el conflicto, el motín para poder acceder al mercado mediante una acción que redujera los precios ${ }^{90}$.

En un momento en que se desarrollaba un conflicto bélico más allá de las murallas, los regentes valencianos no podían permitirse un conflicto interno que pusiera en peligro la defensa de la urbe, de ahí la acción pública para mantener los precios bajos. Sin embargo, hemos podido ver cómo esa misma política provocó un encarecimiento debido a que fue puesta al servicio de la deuda. Parece que ante esta alza provocada por los excesivos gravámenes fiscales respondió un mercado negro que trataba de romper los esquemas dibujados por los munícipes y que encorsetaban las redes legales de comercialización. ¿Habría bajado el precio de haberse canalizado el cereal del mercado negro a través del almudín? La lógica nos dicta que sí, por virtud de la ley de la oferta y la demanda, pero se trataba de un mercado adulterado en el que los comportamientos podrían haber sido muy diferentes a los que suponemos.

En todo caso, al establecer guarniciones cerca de Valencia, Pedro I esperaba que sus incursiones y talas maduraran la conquista de la capital del Turia. Y, sin la política de intervención municipal, seguramente eso habría sido posible. ¿Pero en esa situación cabría esperar que la iniciativa privada fuera dominante? ¿Que el egoísmo se impusiera a la solidaridad? Podemos pensar que se activarían, y probablemente lo hicieron, mecanismos de solidaridad, bien informales, bien formales (cofradías, gremios, fundaciones pías, etc.), pero su grado de efectividad era, por supuesto, mucho menor que la iniciativa pública, aún a pesar de los desequilibrios que ésta pudiera provocar.

Fecha de recepción: 29 de octubre de 2016

Fecha de aceptación: 2 de marzo de 2017

\footnotetext{
89 Luciano Palermo, "Carestia, guerra e mercato nelle cronache medievali", Guerra y carestía en la Europa medieval, Pere Benito i Monclús y Antoni Riera i Melis (coords.), ed. Milenio, Lleida, 2014, pp. 19-34. 90 Este comportamiento, que no llegó a desencadenarse en nuestro contexto, encaja con el concepto de "economía moral de la multitud" acuñado por el historiador E. P. Thompson en la década de 1970 para tratar de explicar el comportamiento de la población inglesa del Antiguo Régimen durante los motines de subsistencias del siglo XVIII; Edward Palmer Thompson, Costumbres en común. Estudios en la cultura popular tradicional, ed. Crítica, Barcelona, 2000.
} 
